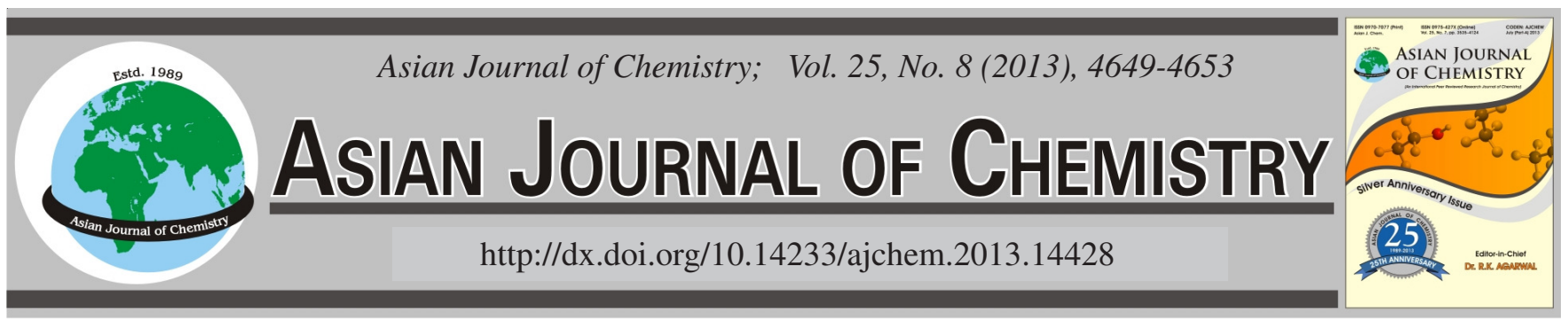

\title{
HPTLC Quantification and Antimicrobial Evaluation of Oleanolic Acid Isolated from Diospyros melanoxylon
}

\author{
Kedar K. Rout ${ }^{1, *}$, Ganeswar Sahoo ${ }^{2}$, Deeptanjali Sahoo ${ }^{3}$ and Rajesh K. Singh ${ }^{1}$
}

${ }^{1}$ Department of Chemistry, North Orissa University, Sriramchandra Vihar, Baripada, Mayurbhanja-757 003, India

${ }^{2}$ Department of Chemistry, Gandhi Institute of Engineering \& Technology, Gunpur-765 022, India

${ }^{3}$ Medicinal Chemistry Department, Central Institute of Medicinal and Aromatic Plants, Lucknow-226 015, India

*Corresponding author: E-mail: kd_rout@yahoo.co.in

(Received: 11 August 2012;

Accepted: 18 February 2013)

AJC-13034

\begin{abstract}
The bioactive molecule, oleanolic acid was isolated from Diospyros melanoxyon leaves by column chromatography and characterized with the help of physical and spectroscopic data. An HPTLC method has been developed and validated for its quantification in $D$. melanoxyon leaves. Chromatographic separation of the compound was achieved on high performance TLC plates by using a binary mobile phase consisting of $n$-hexane:ethyl acetate $(7.5: 2.5, \mathrm{v} / \mathrm{v})$. It was quantified at its wavelength of maximum absorbance of $540 \mathrm{~nm}$ after derivatization with methanol-sulphuric acid reagent. The limit of detection and quantification were found to be 15 and 40 ng per spot, respectively. The linear regression analysis data for the calibration plot showed a good linear relationship between peak area and concentration in the range of 40-360 ng/spot with $\mathrm{r}^{2}=0.9997$. The instrumental precision was $1.18 \%(\mathrm{CV})$ and the repeatability of the method was $1.87 \%(\mathrm{CV})$. The method was validated for precision, recovery and repeatability as per the International Conference on Harmonization guidelines. The developed HPTLC method is accurate, precise and has been successfully applied for the assay of this bioactive molecule in $D$. melanoxylon leaves. Antimicrobial screenings of oleanolic acid revealed its potent activity against a gram positive bacteria viz., S. aureus and four fungal strains viz., A. niger, C. tropicalis, C. albicans and C. krusei.
\end{abstract}

Key Words: High performance thin layer chromatography, Densitometry, Diospyros melanoxylon, Oleanolic acid, Antimicrobial activity.

\section{INTRODUCTION}

Diospyros species are widely distributed in India mostly in the ever green forests of Deccan, Assam and Bengal and a few are in North India ${ }^{1}$. Diospyros melanoxylon (Fam; Ebenaceae) is a middle size tall, green tree with grayish, rough bark and is one of the potent medicinal plant among the 41 species found. It is extensively used in traditional medicine for number of remedies ${ }^{2}$. Phytochemical investigations of the plant revealed the isolation of bioactive compounds like lupeol, betulin, $\beta$-sitosterol, diospyric acid, betulinic acid, ursolic acid, oleanolic acid, $\alpha$-amyrin, corsolic, pomolic, maslinic and jacomouric acids ${ }^{3}$.

During the last two decades pharmacological importance of triterpenes has increased tremendously because of their vast chemical diversity, low toxicity, easy availability and multitarget properties ${ }^{4-8}$. In this prospective, pentacyclic triterpenoids belonging to ursane, oleanane and lupane type are important. Oleanolic acid, a pentacyclic oleanane triterpenoid exists widely in foods and herbs ${ }^{9}$ and identified as one of the active component of Diospyros melanoxylon leaves. It is endowed with varieties of pharmacological effects, such as antifungal ${ }^{10,11}$, insecticidal $^{12}$, anti $\mathrm{HIV}^{13,14}$, diuretic ${ }^{15}$, complement inhibitory ${ }^{16}$, blood sugar depression ${ }^{17}$, antioxidants ${ }^{18}$, antiarrhythmic and cardiotonic $^{19}$, gastrointestinal transit modulating activities ${ }^{20}$. In Chinese medicine, it has been used to treat the liver disorders for over 20 years $^{21}$. In addition, oleanolic acid has been tested successfully to treat liver disease in humans ${ }^{22}$. Recent investigation reveals that the nanoparticulate formulation of oleanolic acid enhances its dissolution rate and bioavailability for many drug delivery systems which provide a feasible formulation method for clinical applications ${ }^{23}$.

Because of interesting biological activities, now-a-days oleanolic acid becomes a hot molecule for the scientists and researchers in the field of pharmacology and medicinal chemistry. Therefore, its content should be accurately determined, to know at which extent this bioactive molecule is accumulated in the D. melanoxylon leaves. In continuation of our research on development of simple and rapid analytical methods for estimation of bioactive molecules in the medicinal 
plants $^{24-26}$, it is therefore needed to develop a rapid and reproducible analytical method for the quantitative determination of oleanolic acid in D. melanoxylon leaves. Further, the possible antimicrobial property of the isolated molecule is to be evaluated against various bacterial and fungal strains by following disc diffusion assay method.

\section{EXPERIMENTAL}

Extraction and isolation of oleanolic acid: The leaves of D. melanoxylon were collected locally, shade dried and powdered. The powdered material $(500 \mathrm{~g})$ was extracted with $n$-hexane. The extract solution was filtered and the volume reduced under pressure. Final drying of the extract yielded $6.45 \mathrm{~g}$ of dark green solid. $5 \mathrm{~g}$ of the extract was chromatograhed over a glass column packed with silica gel (100-200 mesh) and eluted with solvents of increasing polarity from $n$-hexane to $n$-hexane-ethyl acetate mixtures $(40 \%)$. Further purification of fractions and then recrystallization from chloroform-methanol yielded oleanolic acid as a white amorphous powder, m.p. $271^{\circ} \mathrm{C}, \mathrm{R}_{\mathrm{f}}$ : 0.22 ( $n$-hexane:ethyl acetate, $8: 2$, v/v). Its structure was confirmed by analysis of ${ }^{1} \mathrm{H}$ and ${ }^{13} \mathrm{C}$ NMR and mass spectral data.

The HPTLC system (Camag, Muttenz, Switzerland) consisted of a TLC scanner III with winCATS software (version 1.4.2), a Limomat $V$ applicator connected to a nitrogen cylinder, a twin trough chamber $(20 \mathrm{~cm} \times 10 \mathrm{~cm})$, a plate heater, a derivatization chamber and a documentation unit Reproastar 3.

The reagents used during the experiment were of analytical grade and obtained from the SD Fine Chem. Ltd. (Mumbai, India) and HPTLC plates used were from Merck KgaA (Darmstadt, Germany). The standard oleanolic acid was isolated from $D$. melanoxylon leaves.

Preparation of sample and standard solution: An accurately weighed leaf powder of $1 \mathrm{~g}$ was extracted with $n$ hexane in a Soxhlet extractor for $16 \mathrm{~h}$. Extract solution was concentrated under vacuum, filtered and finally made up to $50 \mathrm{~mL}$ in volumetric flask with methanol. The stock solution of pure isolated oleanolic acid was prepared by dissolving $5 \mathrm{mg}$ in $50 \mathrm{~mL}$ mixture of chloroform and methanol $\left(100 \mathrm{ng} \mathrm{mL}^{-1}\right)$. It was further diluted with methanol to prepare the required working standard solution to study the sensitivity, linearity and to perform the validation experiments.

Application of sample and standard solution: The sample and standard solutions were applied onto the plate as $6 \mathrm{~mm}$ band located $10 \mathrm{~mm}$ from bottom and $10 \mathrm{~mm}$ band gap using a Linomat 5 applicator fitted with a $100 \mu \mathrm{L}$ syringe, at a constant application rate of $150 \mathrm{~nL} / \mathrm{s}$. The standard solution of different volumes with concentration range of 5-80 ng each was applied on the TLC plate for the determination of limit of detection (LOD) and limit of quantification (LOQ) of oleanolic acid. Similarly for linearity experiment the standard solution of concentration of $20 \mathrm{ng} \mathrm{mL}^{-1}$ was used and applied to the TLC plate in the concentration range of 40-360 ng. The volume of sample solution was applied to the TLC plate in order to get the concentration of oleanolic acid in the calibrated range.

Chromatography and scanning of plates: Chromatographic separation of the compound was carried out on prewashed and preactivated (at $60{ }^{\circ} \mathrm{C}$ for $0.5 \mathrm{~h}$ ) aluminum foil-backed high performance TLC plates of dimension $10 \mathrm{~cm}$ $\times 10 \mathrm{~cm}$ precoated with a $0.2 \mathrm{~mm}$ layer of silica gel $60 \mathrm{~F}_{254}$. All the applied HPTLC plates containing sample and standard spot were developed with the mobile phase of $n$-hexane: ethyl acetate (7.5: 2.5, v/v) in a Camag twin-trough glass chamber in ascending mode which has been presaturated for $2 \mathrm{~min}$ prior to the chromatography. The solvent front was allowed to reach a height of $84 \mathrm{~mm}$ under the laboratory conditions. Signal-tonoise ratio was used to evaluate LOD and LOQ and determined by using a $5 \mathrm{ng} \mathrm{mL}^{-1}$ standard solution. Oleanolic acid was quantified at $540 \mathrm{~nm}$ (maximum absorbance of wavelength) with the help of Camag TLC Scanner 3 and using winCATS software (version 1.4.2) in absorption-reflection scan mode after derivatization of the plates with methanolic-sulphuric acid reagent $(5 \%)$. The slit dimension of the scanner was set at 5.0 $\mathrm{mm} \times 0.45 \mathrm{~mm}$ (micro) with $100 \mathrm{~mm}$ per step data resolution and $20 \mathrm{~mm} / \mathrm{s}$ scanning speed. The oleanolic acid content was determined from the scan intensity of diffusely reflected light using linear mode of calibration via peak areas.

Antimicrobial evaluation: In vitro antibacterial activity of oleanolic acid was carried out against some selected gastrointestinal tract (GIT) and urinary tract infection (UTI) causing pathogens viz., two gram positive (Staphylococcus aureus, Enterococcus faecalis) and four gram negative (Escherichia coli, Pseudomonas aeruginosa, Klebsiella pneumoniae and Proteus mirabilis) bacterial strains. The antifungal activity was carried against some human pathogenic fungi viz., Aspergillus niger, Candida albicans, Candida tropicalis and Candida krusei by disc diffusion assay method at a concentration of 50 $\mathrm{mg} / \mathrm{disc}(2000 \mathrm{mg} / \mathrm{mL})$ of oleanolic acid. These organisms were identified by standard microbiological method ${ }^{27}$. The antibacterial and antifungal screening of the compound was carried out by determining the zone of inhibition using the disc diffusion assay method ${ }^{28-30}$. Ciprofloxacin $(25 \mu \mathrm{g} / \mathrm{disc})$ and amoxycillin with clavulanic acid $(20+10), 30 \mathrm{mg} / \mathrm{disc}$ were used as standard against gram -ve and gram +ve organisms, respectively for the evaluation of antibacterial activity. Fluconazole (10 mg/disc) and clotrimazole $(10 \mathrm{mg} / \mathrm{disc})$ were used as a standard for antifungal screening.

\section{RESULTS AND DISCUSSION}

Characterization of oleanolic acid: White amorphous powder (0.208 g), m.p. $271^{\circ} \mathrm{C}$; TLC: $\mathrm{R}_{\mathrm{f}}$ : 0.22 (n-hexane:ethyl acetate, 8: 2); IR (KBr, $\left.v_{\max }, \mathrm{cm}^{-1}\right): 3440,2965,1720,1650$, 1460; ${ }^{1} \mathrm{H}$ NMR (DMSO, $400 \mathrm{MHz}$ ): $\delta 5.14$ (t, $1 \mathrm{H}, J=12.2$; $3.5 \mathrm{~Hz}, \mathrm{H}-12), 2.90$ (m, 1H, $J=5.2 \mathrm{~Hz}, \mathrm{H}-3), 2.65$ (dd, 1H, $J$ $=10.2 \mathrm{~Hz}, \mathrm{H}-18), 1.92(\mathrm{dd}, 1 \mathrm{H}, J=12.6 \mathrm{~Hz}, \mathrm{H}-11), 1.10$ (s, $3 \mathrm{H}, \mathrm{H}-27), 0.98$ (s, 3H, H-23), 0.92 (s, 3H, H-30), 0.90 (s, 3H, H-25), 0.85 (s, 3H, H-29), 0.80 (s, 3H, H-24), 0.71 (s, 3H, H26), 11.90 (s, 1H, H-28); ${ }^{13} \mathrm{C}$ NMR (DMSO, $400 \mathrm{MHz}$ ): $\delta$ $178.23\left(\mathrm{C}_{28}\right), 138.15\left(\mathrm{C}_{13}\right), 124.55\left(\mathrm{C}_{12}\right), 76.80\left(\mathrm{C}_{3}\right), 54.75\left(\mathrm{C}_{5}\right)$, $52.35\left(\mathrm{C}_{9}\right), 46.86\left(\mathrm{C}_{19}\right), 46.79\left(\mathrm{C}_{17}\right), 41.61\left(\mathrm{C}_{18}\right), 41.36\left(\mathrm{C}_{14}\right)$, $39.92\left(\mathrm{C}_{8}\right), 39.71\left(\mathrm{C}_{4}\right), 38.87\left(\mathrm{C}_{1}\right), 38.40\left(\mathrm{C}_{10}\right), 36.49\left(\mathrm{C}_{29}\right)$, $36.34\left(\mathrm{C}_{21}\right), 34.27\left(\mathrm{C}_{22}\right), 32.66\left(\mathrm{C}_{7}\right), 30.16\left(\mathrm{C}_{20}\right), 28.22\left(\mathrm{C}_{23}\right)$, $27.50\left(\mathrm{C}_{15}\right), 26.95\left(\mathrm{C}_{2}\right), 26.36\left(\mathrm{C}_{27}\right), 23.99\left(\mathrm{C}_{30}\right), 23.77\left(\mathrm{C}_{16}\right)$, $23.23\left(\mathrm{C}_{11}\right), 17.96\left(\mathrm{C}_{6}\right), 16.96\left(\mathrm{C}_{26}\right), 15.98\left(\mathrm{C}_{24}\right), 15.18\left(\mathrm{C}_{25}\right)$; MS (m/z, \%): $456\left(\mathrm{M}^{+}\right), 248$ (100), 207, 204, 189, 175 and 133. The spectral data was further confirmed with reported literature ${ }^{31}$. 
Development of optimum mobile phase: The mobile phase plays a crucial role during the HPTLC analysis for the exact measurement of analytes. A number of mobile phases have been tried in order to get dense, compact spots with appropriate and significantly differ in $\mathrm{R}_{\mathrm{f}}$ values of the components present in the crude extract. Among the solvent system investigated during the TLC study, $n$-hexane:ethyl acetate (7.5: $2.5, \mathrm{v} / \mathrm{v}$ ) was found to give good separation of oleanolic acid from other components with symmetrical chromatogram. The $\mathrm{R}_{\mathrm{f}}$ value was found to be 0.25 with the solvent migration distance of $84 \mathrm{~mm}$ and the chamber saturation time of $3 \mathrm{~min}$.

HPTLC method development and validation: Validation of the developed HPTLC method was carried out as per the International Conference on Harmonization ( $\mathrm{ICH}$ ) guidelines Q2 (R1) for specificity, sensitivity, linearity, accuracy, precision, repeatability and robustness ${ }^{32,33}$. The sensitivity of the method was tested with respect to limit of detection (LOD) and limit of quantification (LOQ) of oleanolic acid. Under the experimental conditions, the LOD and LOQ were found to be 15 and $40 \mathrm{ng}$ per spot, respectively. The linearity of the method was tested at five concentration levels of oleanolic acid i.e., 40, 120, 200, 280 and $360 \mathrm{ng} / \mathrm{spot}$ and was presented by linear equation $y=8.577 x+35.196$ with a correlation co-efficient of the calibration plot 0.9997 , indicating a good linear relationship between peak area and concentration (Fig. 1). Instrumental precision was checked by scanning of six bands of oleanolic acid at a concentration of $300 \mathrm{ng} / \mathrm{spot}$ by the proposed method. The coefficient of variation of measurement of the peak area was taken to evaluate the system precision and was found as 1.18 (Table-1).

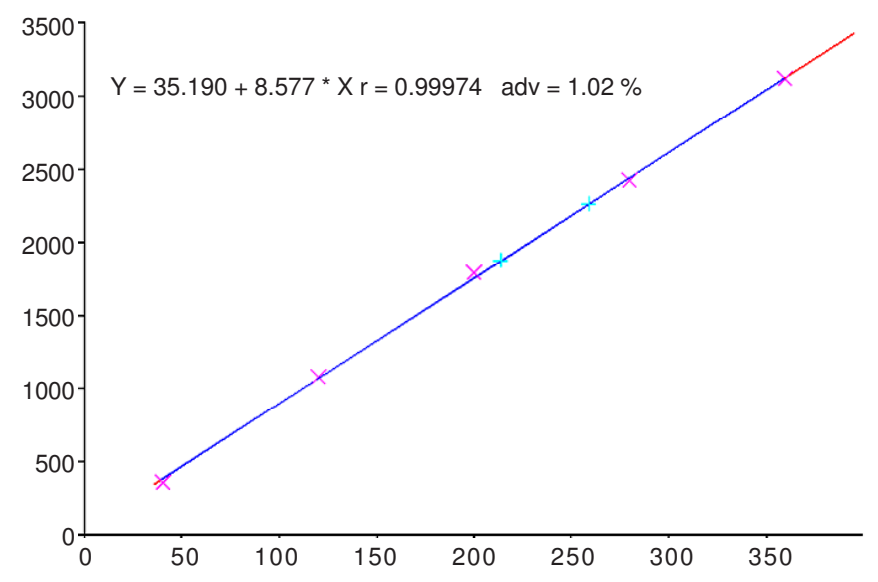

Fig. 1. Linear calibration plot of oleanolic acid

Intra-day precision of the method was assessed for oleanolic acid at three different concentrations (120, 200 and $280 \mathrm{ng} / \mathrm{spot})$ over entire calibration range for six time $(\mathrm{n}=6)$ on the same day, whereas inter-day precision was checked at the same concentration level over entire calibration range for six time $(n=6)$ on the consecutive days. In both cases, the coefficient of variation of peak area of spot was used to evaluate the method precision (Table-2). Accuracy of the method was studied by performing the recovery experiment, which was carried out by spiking a known amount of oleanolic acid at 3 different levels with 3 replicates for each level and the CV was calculated. A satisfactory recovery varies from 97.51-
TABLE-1

METHOD VALIDATION DATA FOR OF OLEANOLIC ACID

\begin{tabular}{lc}
\multicolumn{1}{c}{ Parameters } & Data \\
\hline Instrument precision $(\mathrm{CV} \%, \mathrm{n}=6)^{\mathrm{a}}$ & 1.18 \\
Repeatability $(\mathrm{CV} \%, \mathrm{n}=6)^{\mathrm{a}}$ & 1.87 \\
Limit of detection $(\mathrm{ng} / \mathrm{spot})$ & 15 \\
Limit of quantification (ng/spot) & 40 \\
Correlation coefficient $(\mathrm{r})$ & 0.9997 \\
Linearity range $(\mathrm{ng} / \mathrm{spot})$ & $40-360$ \\
Standard deviation $(\%)$ & 1.62 \\
Number of data points & 5 \\
RSD of slope & 1.83 \\
RSD of intercept & 2.55 \\
Robustness & Robust \\
Specificity & Specific \\
\hline${ }^{\mathrm{a}} \mathrm{n}=$ Number of determinations. &
\end{tabular}

TABLE-2

INTRADAY AND INTERDAY PRECISION STUDY OF THE METHOD ${ }^{\mathrm{a}}$

\begin{tabular}{cccccc}
\hline \multirow{2}{*}{ Compound } & $\begin{array}{c}\text { Concentration } \\
(\mathrm{ng} / \mathrm{spot})\end{array}$ & $\begin{array}{c}\text { Intraday precision } \\
\text { area }\end{array}$ & $\begin{array}{c}\text { RSD } \\
(\%)\end{array}$ & $\begin{array}{c}\text { Mean } \\
\text { area }\end{array}$ & $\begin{array}{c}\text { RSD } \\
(\%)\end{array}$ \\
\hline \multirow{2}{*}{ Oleanolic } & 120 & 1383.56 & 1.67 & 1395.14 & 1.89 \\
acid & 200 & 2238.11 & 1.84 & 2247.39 & 1.78 \\
& 280 & 3183.38 & 1.49 & 3211.54 & 1.94 \\
\hline $\mathrm{a} n=6$. & & & & \\
\end{tabular}

$98.39 \%$ with an average value of $97.88 \%$ for oleanolic acid was obtained using the proposed method. The results are presented in Table- 3 .

The specificity of the method was confirmed by comparing the absorption spectra of the standard oleanolic acid with the bands at same corresponding $\mathrm{R}_{\mathrm{f}}$ value in the sample track; they were found to be superimposable (Fig. 2). The peak purity of the separated oleanolic acid was tested by its UVvisible absorption spectra at its maximum absorbance of wavelength and compared with an experimental correlation limit of 0.99900; it was found that correlation coefficient (r) start to middle $=0.99996$ and middle to end $=0.99979$ which indicated that all the standard peaks satisfactorily passed the purity test (Fig. 3). The robustness of the method was tested by small deliberate changes in the composition of the mobile phase and analysis of oleanolic acid. There was no significant change in the $\mathrm{R}_{\mathrm{f}}$ of the compound which confirmed the robustness of the method.

Quantification of oleanolic acid: The proposed method was applied for the determination of oleanolic acid in $D$. melanoxylon leaves. Six replicate determinations were made and the average content was recorded as $0.369 \%$.

Antimicrobial activity: The results of antibacterial and antifungal activities in terms of zone of inhibition are presented in Table-4. Oleanolic acid exhibited highest zone of inhibition against bacterial strains $S$. aureus and E. faecalis followed by $K$. pneumoniae, $P$. aeruginosa and $P$. mirabilis and no inhibitory activity was observed for E. coli. Potent activity was observed against the gram +ve bacteria $S$. aureus, whereas it showed moderate activity against a gram -ve bacterial, K. pneumoniae. It showed potent activity against all the fungal strains tested and exhibited highest zone of inhibition against $A$. niger followed by $C$. krusei, $C$. tropicalis and $C$. 
TABLE-3

RECOVERY STUDY OF OLEANOLIC ACID BY HPTLC

\begin{tabular}{cccccccc}
\hline \multirow{2}{*}{ Compound } & $\begin{array}{c}\text { Amount present in } \\
(2 \mu \mathrm{L}) \text { the sample }(\mathrm{ng})\end{array}$ & $\begin{array}{c}\text { Amount spiked } \\
(\mathrm{ng})\end{array}$ & $\begin{array}{c}\text { Amount found } \\
(\mathrm{ng})\end{array}$ & $\begin{array}{c}\mathrm{CV} \\
(\mathrm{n}=3)\end{array}$ & $\begin{array}{c}\text { Recovery } \\
(\%)\end{array}$ & $\begin{array}{c}\text { Average recovery } \\
(\%)\end{array}$ \\
\hline \multirow{3}{*}{ Oleanolic acid } & 219.4 & 40 & 252.94 & 1.68 & 97.51 & \\
& 220.7 & 80 & 295.85 & 1.37 & 98.39 & 97.88 \\
& 220.2 & 120 & 332.50 & 1.72 & 97.74 & \\
\hline
\end{tabular}

${ }^{a}$ Each value is the mean of three analyses.
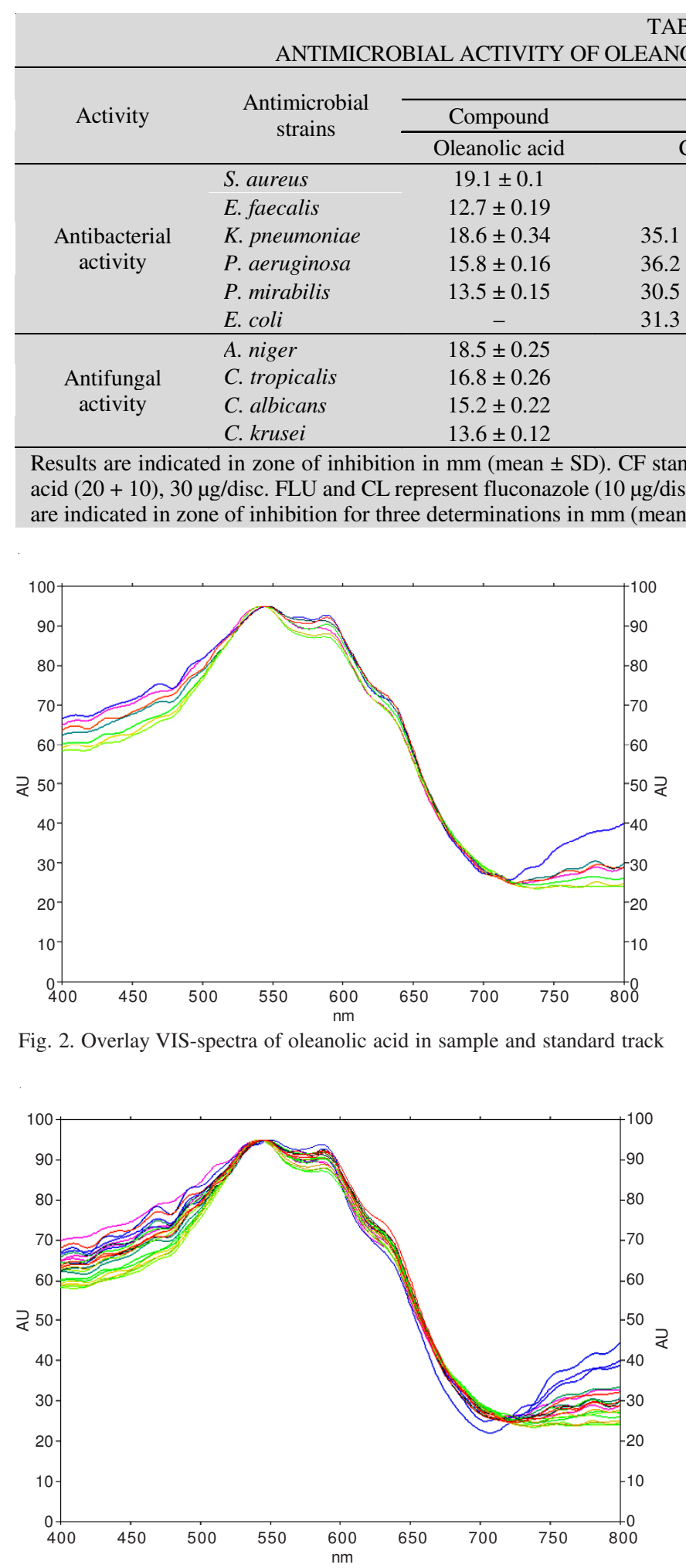

Fig. 3. Overlay VIS-spectra for purity study of oleanolic acid in sample and standard track are indicated in zone of inhibition for three determinations in mm (mean $\pm \mathrm{SD})$.
Fig. 2. Overlay VIS-spectra of oleanolic acid in sample and standard track

TABLE-4

ANOLIC ACID BY DISC-DIFFUSION METHOD

Zone of inhibition in $\mathrm{mm}$

\begin{tabular}{cccc}
\multicolumn{5}{c}{ Standards } & FLU \\
CF & AC & CL & - \\
- & $25 \pm 0.35$ & - & - \\
- & $19.7 \pm 0.70$ & - & - \\
$5.1 \pm 0.58$ & - & - & - \\
$6.2 \pm 0.42$ & - & - & - \\
$0.5 \pm 0.35$ & - & - & - \\
$1.3 \pm 0.53$ & - & - & - \\
- & - & $21.1 \pm 0.2$ & $22.2 \pm 0.3$ \\
- & - & - & $21.6 \pm 0.22$ \\
- & - & - & $17.7 \pm 0.23$ \\
- & - & - & -
\end{tabular}

ands for ciprofloxacin $25 \mu \mathrm{g} /$ disc. AC stands for Amoxycillin + Clavulanic acid $(20+10), 30 \mu \mathrm{g} /$ disc. FLU and CL represent fluconazole $(10 \mu \mathrm{g} /$ disc $)$ and clotrimazole $(10 \mu \mathrm{g} /$ disc $) .-$ indicates no zone of inhibition. Results

albicans. The percentage zone of inhibition was found highest against $A$. niger followed by $C$. tropicalis and C. krusei and least for $C$. albicans when compared with standards.

\section{Conclusion}

A quantitative chromatographic method has been reported for the first time for quantification of the biologically active component, oleanolic acid in D. melanoxylon leaves. The developed HPTLC method was successfully validated as per the ICH guidelines and statistical data proves that the method is sensitive, specific, accurate and repeatable. The antimicrobial screening revealed that the molecule showed potent activity against a gram positive bacteria, $S$. aureus and four fungal starins viz., A. niger, C. tropicalis, C. albicans and C. keusei. The $D$. melanoxylon leaves accumulate significant level of this mportant bioactive molecule and it may be used as an alternative source for this bioactive molecule.

\section{ACKNOWLEDGEMENTS}

The authors thank the Head, Department of Chemistry, North Orissa University for providing the necessary facilities for performing this research work and also to the scientific officer, Dr. Acharya, Ayurvedic Drug Testing Laboratory, Bubaneswar and Dr. S. Sahoo, University Department of Pharmaceutical Sciences, Utkal University for their valuable support.

\section{REFERENCES}

1. M.B. George Watt, A Dictionary of the Economic Products of India, Vol. III, Cosmopublication, New Delhi, India, p. 136 (1952).

2. B.N. Sastry, In the Wealth of India, Raw Materials, (CSIR, New Delhi), Vol. 3, p. 76 (1952)

3. K.K. Rout, R.K. Singh and S.K. Mishra, J. Planar. Chromatogr., 24, 376 (2011).

4. P.K. Chaturvedi, K. Bhui and Y. Shukla, Cancer Lett., 263, 1 (2008). 
5. S. Fulda, Int. J. Mol. Sci., 9, 1096 (2008).

6. S. Alakurtti, T. Makela, S. Koskimies and J. Yli-Kauhaluoma, Eur. J. Pharm. Sci., 29, 1 (2006).

7. J. Liu, J. Ethnopharmacol., 100, 92 (2005).

8. S. Jager, M.N. Laszczyk and A. Scheffler, Molecules, 13, 3224 (2008).

9. J. Liu, J. Ethnopharmacol., 49, 57 (1995).

10. H.Q. Tang, J. Hu, L. Yang and R.X. Tan, Planta Med., 66, 391 (2000).

11. T.S. Jeong, E.I. Hwang, H.B. Lee, E.S. Lee, Y.K. Kim, B.S. Min, K.H Bae, S.H. Bok and S.U. Kim, Planta Med., 65, 261 (1999).

12. S. Marquina, N. Maldonado, M.L. Garduno-Ramirez, E. Aranda, M.L. Villarreal, V. Navarro, R. Bye, G. Delgado and L. Alvarez, Phytochemistry, 56, 93 (2001).

13. Y. Kashiwada, T. Nagao, A. Hashimoto, Y. Ikeshiro, H. Okabe, L.M. Cosentino and K.H. Lee, J. Nat. Prod., 63, 1619 (2000).

14. C. Ma, N. Nakamura, M. Hattori, H. Kakuda, J. Qiao and H. Yu, J. Nat. Prod., 63, 238 (2000).

15. M.E. Alvarez, A.O. Maria and J.R. Saad, Phytother. Res., 16, 71 (2002).

16. H. Assefa, A. Nimrod, L. Walker and R. Sindelar, Bioorg. Med. Chem. Lett., 11, 1619 (2001).

17. M. Yoshikawa and H. Matsuda, Biofactors, 13, 231 (2000).

18. S. Balanehru and B. Nagarajan, Biochem. Int., 24, 981 (1991).

19. L.I. Somova, F.O. Shode and M. Mipando, Phytomedicine, 11, 121 (2004).

20. Y. Li, H. Matsuda and M. Yoshikawa, Bioorg. Med. Chem., 7, 1201 (1999).

21. X. Wang, X.L. Ye, R. Liu, H.L. Chen, H. Bai, X. Liang, X.D. Zhang, Z. Wang, W.L. Li and C.X. Hai, Chem. Biol. Interact., 184, 328 (2010).
22. Human Medical Institute, Tradit. Med., 8, 32 (1997).

23. M. Chen, Z. Zhong, W. Tan, S. Wang and Y. Wang, Chin. Med., 6, 20 (2011).

24. K.K. Rout, S. Mishra, S.K. Mishra and S. Sahoo, Food, 3, 73 (2009).

25. K.K. Rout, S.K. Mishra and J. Sherma, Acta Chromatogr., 21, 443 (2009).

26. K.K. Rout and S. Mishra, J. Planar Chromatogr., 22, 127 (2009).

27. P.R. Murray, E.J. Barron, M.A. Pfaller, F.C. Tenover and R.H. Yolken, Manual of Clinical Microbiology, American Society for Microbiology, Washington, DC, edn. 6 (1995)

28. S. Mishra, S. Sahoo, S.K. Mishra, K.K. Rout, S.K. Nayak and N.K. Dhal, Med. Arom. Plant. Sci. Biotechnol., 3, 55 (2009).

29. M.J. Pelczar, E.C.S. Chan and N.R. Krieg, Microbiology, Tata McGraw Hill, New Delhi, edn. 5, p. 137 (2005).

30. Annonymous, Indian Pharmacopoeia, The Controller of Publication, New Delhi, p. 100 (1996).

31. W. Seebacher, N. Simic, R. Weis, R. Saf and O. Kunert, Magne. Reson. Chem., 41, 636 (2003).

32. Validation of Analytical Procedure, Methodology Q2 (R1), International Conference on Harmonization (ICH), International Federation of Pharmaceutical Manufacturers and Associations (IFPMA), Geneva, Switzerland (1996)

33. K.K. Rout and S.K. Mishra, J. Planar Chromatogr., 22, 127 (2009). 